\title{
Operational Characteristics of Paratransit Services with Ride-Hailing Apps in Asian Developing Cities: The Phnom Penh Case
}

\author{
Veng Kheang Phun'1, Reiko Masui' ${ }^{2}$, Tetsuo Yai ${ }^{3}$ \\ ${ }^{1}$ Research Department, Japan Transport and Tourism Research Institute, Tokyo, Japan \\ ${ }^{2}$ The Institute of Innovative Research, Tokyo Institute of Technology, Tokyo, Japan \\ ${ }^{3}$ Built Environment Department, Tokyo Institute of Technology, Tokyo, Japan \\ Email: kheang@jterc.or.jp, masui.r.aa@m.titech.ac.jp, tyai@enveng.titech.ac.jp
}

How to cite this paper: Phun, V.K., Masui, R. and Yai, T. (2018) Operational Characteristics of Paratransit Services with Ride-Hailing Apps in Asian Developing Cities: The Phnom Penh Case. Journal of Transportation Technologies, 8, 291-311. https://doi.org/10.4236/jtts.2018.84016

Received: August 31, 2018

Accepted: October 15, 2018

Published: October 18, 2018

Copyright () 2018 by authors and Scientific Research Publishing Inc. This work is licensed under the Creative Commons Attribution International License (CC BY 4.0).

http://creativecommons.org/licenses/by/4.0/

\begin{abstract}
Rapid adoption of ride-hailing apps (RHAs) has greatly influenced the way people travel-there is no exception for paratransit users. However, it remains unclear whether RHAs would be regarded as threats or opportunities among paratransit operators in Asian developing cities. While RHAs have been viewed as disruptive transportation, several studies explored the threats of RHAs on taxi industry-but only a few examined such threats on other paratransit services (e.g., auto-rickshaws). This study assessed the changes in the operational services among paratransit operators who have adopted RHAs. The changes were examined by statistical comparisons using data collected from questionnaire survey with 182 Bajaj drivers in Phnom Penh, January 23-27, 2018, as a case study. Results showed that majority of the interviewed drivers started new services with RHAs less than a year ago-they were younger ( $<40$ years old), married, and higher education. After adopting RHAs, the drivers could increase their revenue by increasing the number of trips and customers. They could further achieve a higher revenue by operating with multiple RHAs. Most drivers (>88\%) satisfied with RHAs and acknowledged improvements on their operational services. The results suggested that RHAs would be opportunities for those paratransit drivers who have adopted them, while they would be threats for those who have not. The collected data serve as useful inputs for future public transport planning in Asian developing cities.
\end{abstract}

\section{Keywords}

Asian Developing City, Operational Characteristics, Ride-Hailing App,

Paratransit, Phnom Penh 


\section{Introduction}

Ride-hailing applications (RHAs) have experienced significant growth in adoption worldwide, since the introduction of Uber in 2009 [1] [2]. Thanks to the rapid development of mobile and wireless communication technologies, the smartphones with GPS, internet, and digital road maps have enabled ride-hailing service (RHS) via RHAs. In recent years, many RHAs (e.g., Didi, Grab, Easy, Lyft, and Ola Cabs) have been established as an online-platform to connect customers and transport operators, facilitate their matching, and allow them to communicate more efficiently. RHAs improve the quality of on-demand transport services such as safety, convenience, and seamless experience [3] - and in particular, shorter waiting time could be an attractive feature of RHAs [4].

RHS has a great influence on the way people travel [5] - this is also the case for paratransit users. In Asian developing countries, more RHAs have been developed and expanded for non-fixed route paratransit modes such as taxis, auto-rickshaws, motorcycle taxis, and cycle-rickshaws [6]. Figure 1 shows the overall expansion of RHAs in some of these countries. The first RHA was GO-JEK, which has been introduced in Indonesia since 2010. The number of RHAs increased significantly from 2013. Traditionally, citizens hail for an empty-cruising paratransit on-streets or look for it at a particular pick-up station along the streets (e.g., near markets and intersections). Instead of hailing paratransit on-streets, citizens can now easily hail for paratransit with the press of a button on RHAs in their smartphones, and GPS takes care of the locations. RHAs notably help citizens to overcome the previous information barriers caused by spatial deviation between paratransit users and drivers-and are thus believed to be a powerful instrument for improving efficiency of paratransit market [7]. It should be noted that the advanced utilization of the old-fashioned paratransit modes with innovative technologies (e.g., electric vehicle, fare system, and RHAs) might be equally conceptualized as "LAMAT: Locally Adapted, Modified, and Advanced Transport". LAMAT refers to the indigenous public transport modes that are locally, adapted, modified, and advanced for a certain transport service in a particular city or region [8]. The concept of "LAMAT" has been motivated by at least two major reasons: 1) because the concepts of paratransit are quite different between developed and developing countries, and 2) because numerous descriptions (e.g., informal transport, indigenous transport, or third-world transport) have been given for paratransit in Asian developing countries. To this end, the term "LAMAT" has been recommended when referring to the term "paratransit" in Asia.

The growing popularity of RHAs as mobility services has been seen as disruptive transportation [1] [9]. Because RHS does not comply with the traditional rules, it is also seen as a threat to existing transport operators-while policymakers have considered new regulations for RHS. In China, for example, the traditional taxi drivers have protested at numerous cities against the unfair competition (e.g., fare) from RHAs since 2015. To address the growing issues of 


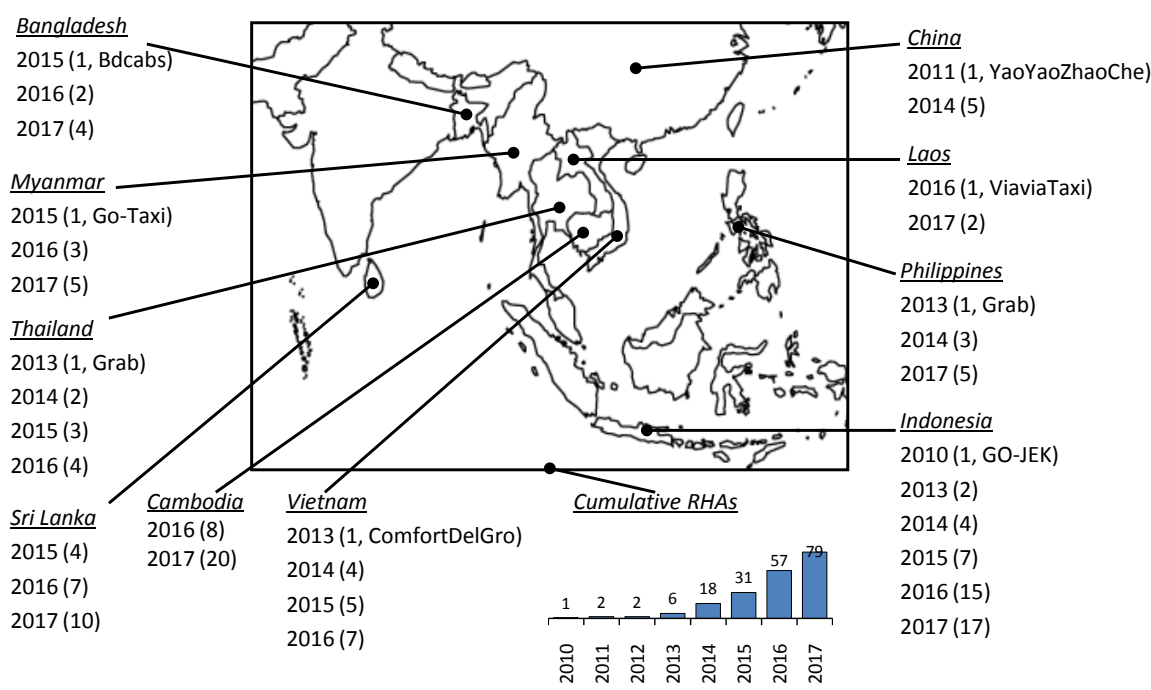

Figure 1. The cumulative number of ride-hailing apps (in parentheses) by years in some Asian countries. The first app name is also shown in the parentheses (Source: https://play.google.com).

RHAs, in July 2016, China established new regulations to govern all for-hire services. The new Chinese regulations provide basic principles for local governments to create innovative and flexible (de-)regulation on supply quantity, fare, labor protection, and market entry [10]. In the Philippines, RHS has not yet been considered as a disruptive innovation-that is, the traditional taxi industry can still compete with RHAs [3]. While regular taxi operators continue to protest against RHAs, they fail to realize and prioritize the needs faced by both customers and drivers. The Philippines has viewed RHAs as safer and more convenient commuting options for citizens, and established legal framework to regulate RHS and to tackle with the increasing urban mobility. In Thailand, there have been conflicts between ride-hailing firms (RHFs) and paratransit operators [11]. In May 2016, Department of Land Transport (DLT) banned UberMoto and GrabBike for violations of existing public transport regulations including license and fare. In July 2016, GoBike was launched as the Thailand's first official and fully legal RHA for motorcycle taxis, that complied with the strict regulations set by the DLT. Later, the RHFs conformed the national regulations and pursued strategies to attract more drivers. For example, Grab Thailand introduced a financial incentive (i.e., $1000 \mathrm{THB}$ ) campaign to draw more motorcycle taxi drivers into GrabBike. As Grab did not have enough drivers with motorcycles registered as public vehicle under Thai laws (i.e., yellow-plated license), Grab also recruited drivers with unregistered motorcycles (i.e., white-plated license) for providing RHS. The new business model of RHAs, however, is very different from the traditional motorcycle taxi services-which are mostly organized as groups (know as Win in Thai) and operated within pre-defined servicing areas [12]. Since RHA drivers could pick up a customer anywhere, this has created conflicts when Win members realized that RHA drivers picked up customers from their 
servicing areas. As a result, in March 2018, Win members gathered and protested against RHAs (i.e., GrabBike and GoBike)-by calling on the RHFs to stop owners of white-plated motorcycles from providing services, and the government to consider appropriate policy intervention.

Many studies assessed the impacts of RHAs on existing transport services [9] [13] [14]. The studies can be categorized into "rule change" from the viewpoint of market regulation, "competitive effects" from an industry standpoint, and "labor changes" from the stakeholder perspective [10]. The impact assessment is quite important for successfully designing appropriate regulations for RHS particularly in Asian developing cities in the long run. While several RHA studies concern taxi industry[3] [4] [13] [15] [16], only few concern other paratransit modes such as motorcycle taxis and auto-rickshaws [17]. With lack of literature, it remains unclear whether RHAs would be regarded as threats or opportunities among paratransit operators in Asian developing cities. Given the long-term transport policy decisions, there is a need to collect data on operational characteristics of paratransit drivers who have adopted RHAs, and assess the potential impacts of RHAs on their operational services. With such data, one would know better how RHAs might support or impede goals for mobility, safety, and environmental sustainability.

This study assesses changes in the operational characteristics among paratransit operators who have adopted RHAs in Asian developing cities. The changes are examined via data from questionnaire survey conducted with paratransit drivers with RHAs in Phnom Penh, as a case study. We also use a GPS device to measure operating speed and routes of the RHA drivers. This might be the first study showing how paratransit operators would view RHS and how RHS would influence their operational services in the context of Asian developing countries. This study contributes to the limited literature on this topic by adding details on the changes in operational and behavioral characteristics among paratransit drivers, who have embraced innovative technology (i.e., RHAs) to advance their informal transport services. The collected data might also serve as useful information for guiding policymakers to design applicable and flexible regulations for RHS in Asia.

\section{Phnom Penh at a Glance}

\subsection{Urban Transport}

Phnom Penh, the capital city of Cambodia, has $678.5 \mathrm{~km}^{2}$ of land area, with population estimated to be 2.4 million in 2020 [18]. The GPD per capita increased from 981 USD in 2009 to 1435 USD in 2017. The number of person trips was also expected to increase from 4.3 million in 2012 to 7.0 million trips in 2035. The modal share in 2012 was as follows: car (8.0\%), motorcycle (51.8\%), bicycle $(9.1 \%)$, walking (14.9\%), public transport (15.4\%), and others $(0.8 \%)$. There was no mass transit system, and the available public transport modes at that time were mainly paratransit. Following the rapid urbanization, the traffic 
issues in the city have become worse. Mass transit systems including intra-city public bus, bus rapid transit, light rail transit, Skyrail, Tramway have been considered as alternative solutions to cope with the increasing traffic issues.

The current urban public transport modes include public bus and paratransit. The bus is the only available mass transit system, which has been introduced since 2014. From September 2017, the bus services have been expanded to ten routes (total length of $148 \mathrm{~km}$ ), covering several parts of the city [19]. Since the bus is operated in mixed traffic, its operating speed is relatively slow (approximately $10 \mathrm{~km} / \mathrm{h}$ ) and the expected waiting time at a bus stop is uncertain. In addition, $40.0 \%$ of the bus users appear to be free riders [20], which leads to concern over overall revenue of bus operations. However, the bus service is still rather new and seems to have little appeal to general citizens because many still prefer door-to-door trips. This also includes the poor accessibility (e.g., sidewalk, weather conditions, safety and security) to a bus stop. Although the public buses play a vital role in any urban area, their services are frequently insufficient to meet the demand [21] — and many citizens thus depend on paratransit services.

Paratransit modes in Phnom Penh include Motodop, Auto-rickshaws, and Cyclo [22]. Motodop refers to motorcycle taxi, which can typically transport a maximum of two adults and one child. Auto-rickshaws include Remorks and motorized three-wheelers. Remork is a rickshaw dragged by a motorcycle, transporting 2 - 6 passengers. Remork is sometimes known as three-wheeler or Tuktuk, despite being a four-wheeled vehicle. Motodops and Remorks have been popular modes in the city. Recently, more motorized three-wheelers (e.g., Bajaj) has also been observed on city streets. Cyclo is a non-motorized three-wheeler powered by human (1 - 2 passengers). Cyclo was popular since a long time ago, but it is now used mainly for short-distance trip and is mostly preserved for tourist demand. According to Cyclo Conservation and Careers Association, the number of Cyclos in Cambodia decreased from approximately 1500 in 2007 to 700 in 2012.

Registration of auto-rickshaws has started since 2009. According to the Department of Public Work and Transport, the number of registered Remorks in Phnom Penh increased from 1423 in 2009 to 7289 in 2012. By February 2018, the total number of registered auto-rickshaws reached 18,030-among which, there were 10,091 Remorks, 3282 Bajajs, and 4659 Chinese motorized tricycles. Bajajs refer to the imported motorized three-wheeler from India. However, the number of Motodops remains unknown because there is no official control or record over the operations of Motodops (e.g., license and registration). Anyone who owns a motorcycle can become a Motodop driver if he/she wants to do so.

\subsection{Ride-Hailing Service}

In Cambodia, we conducted two online searches in Google Play website to see the number of RHAs and their popularity for one-year period, September 2017 and August 2018. The popularity of an RHA is conceptually assessed by the 
number of android installs reported in the Google Play website (i.e., not iOS devices). Table 1 summarizes the search results. It shows that there were at least 20 RHAs, two of which were from international RHFs (i.e., Grab and Uber). Uber launched its services in Cambodia in September 28, 2017, while Grab followed in December 19, 2017. In March 2018, Uber agreed to combine its business operations in Southeast Asia with Grab-one possible reason was due to extreme completions with local RHAs-as an exchange, Uber would get a $27.5 \%$ stake in the combined firms.

Among local RHFs, some RHAs become more popular (e.g., PassApp, iTsumo, and WeGo) while some RHAs become less popular or disappeared (e.g., Exnet, CamGo, Natra), as evidenced by the changes in the number of android installs. Each RHA has been developed separately for drivers and general users. In particular, PassApp has become the most popular paratransit RHAs-the number of its installs by users and drivers increased by ten times within the observed period, indicating high acceptance among general citizens and paratransit drivers in Phnom Penh. PassApp has also planned to expand its services for Motodop and to other provinces (e.g., Siem Reap). Grab has already expanded to Siem Reap. Moreover, we observed that most RHFs require the registered paratransit drivers to attach an RHA logo sticker on their vehicles or wear a uniform, indicating the RHF with which they operate.

\section{Data}

We use questionnaire survey to collect data about the operational characteristics of paratransit drivers, who have operated with RHAs in Phnom Penh. The questionnaire was first written in English and was later translated into Khmer. We then verified its consistency between the English and Khmer versions in a pilot test. The questionnaire includes five parts. Part 1 inquired about RHAs in general. Part 2 inquired about the changes in the operational services after adopting RHAs. Part 3 inquired about the behaviors of paratransit drivers when waiting for customers booking via RHAs. Part 4 inquired about subjective responses towards RHAs. The subjective questions were based on a 5-point scale (1: very unlikely, 2: unlikely, 3: neither, 4: likely, 5: very likely). And part 5 inquired about personal information.

Four surveyors were trained to fully understand and administered the questionnaire. There were no specific interview locations had been pre-defined. Paratransit drivers operated with RHAs were acquired by three different methods. First, surveyors sought for RHA drivers on city streets by a visual inspection. They approached the drivers whose vehicles were attached with RHA logos. Second, surveyors visited RHA companies. There, the drivers who already registered to RHAs came to pay for the commission fee or have their vehicles maintained. And third, surveyors made a booking via RHAs, calling drivers to a designated location. The shortest trip-distance was selected for minimum fare. Upon arrival, the drivers were queried whether they would participate in the survey. Yet, only four drivers were recruited using this method. 
Table 1. The number of ride-hailing apps and their popularity in Cambodia.

\begin{tabular}{|c|c|c|c|c|c|c|}
\hline \multirow{3}{*}{ No. } & \multirow{3}{*}{ RHAs } & \multirow{3}{*}{ Modes } & \multicolumn{4}{|c|}{ Number of Android Installs } \\
\hline & & & \multicolumn{2}{|c|}{ September 2017} & \multicolumn{2}{|c|}{ August 2018} \\
\hline & & & Users & Drivers & Users & Drivers \\
\hline \multicolumn{7}{|c|}{ Cambodia } \\
\hline 1 & PassApp & $\mathrm{CT}, \mathrm{AR}$ & $10,000+$ & $1000+$ & $100,000+$ & $10,000+$ \\
\hline 2 & Exnet & $\mathrm{CT}, \mathrm{AR}$ & $10,000+$ & $500+$ & $10,000+$ & $1000+$ \\
\hline 3 & UGO711 & $\mathrm{CT}, \mathrm{AR}$ & $5000+$ & $100+$ & $10,000+$ & $5000+$ \\
\hline 4 & iTsumo & $\mathrm{CT}, \mathrm{AR}$ & $5000+$ & $1000+$ & $10,000+$ & $1000+$ \\
\hline 5 & Choice Taxi & $\mathrm{CT}$ & $1000+$ & & $5000+$ & \\
\hline 6 & CamGo & $\mathrm{CT}, \mathrm{AR}, \mathrm{MC}$ & $1000+$ & $1000+$ & $10+$ & $50+$ \\
\hline 7 & Taxi Meter KH & $\mathrm{CT}$ & $500+$ & & $1000+$ & \\
\hline 8 & Go TukTuk & $\mathrm{AR}$ & $500+$ & & & \\
\hline 9 & Let'sGO & $\mathrm{CT}$ & $100+$ & & & \\
\hline 10 & Natra & $\mathrm{CT}, \mathrm{AR}, \mathrm{MC}$ & $100+$ & $100+$ & & \\
\hline 11 & Taxigoal & $\mathrm{CT}, \mathrm{AR}$ & $100+$ & & & \\
\hline 12 & 711Go-X & $\mathrm{CT}$ & $100+$ & $10+$ & & \\
\hline 13 & Easy Rider & $\mathrm{CT}$ & $100+$ & $10+$ & $100+$ & $100+$ \\
\hline 14 & WeGo & $\mathrm{CT}, \mathrm{AR}$ & $50+$ & & $10,000+$ & $10,000+$ \\
\hline 15 & Calltaxi & $\mathrm{CT}$ & $10+$ & $10+$ & & \\
\hline 16 & FastGo & $\mathrm{AR}$ & & & $10,000+$ & $1000+$ \\
\hline 17 & TosTov & $\mathrm{CT}, \mathrm{AR}$ & & & $1000+$ & $1000+$ \\
\hline 18 & Taxi Cambodia & $\mathrm{CT}$ & & & $50+$ & $10+$ \\
\hline \multicolumn{7}{|c|}{ Cambodia and other countries } \\
\hline 19 & Grab & $\mathrm{CT}, \mathrm{MC}$ & 10 mil.+ & & 50 mil.+ & 5 mil.+ \\
\hline 20 & Uber & $\mathrm{CT}$ & 100 mil.+ & & 100 mil.+ & 10 mil.+ \\
\hline
\end{tabular}

Note: RHA: Ride-hailing app, CT: Cars or Taxis, AR: Auto-rickshaws, MC: Motorcycle. Source: https://play.google.com.

The surveyors did not target all paratransit drivers with RHAs they spotted. They first observed if a driver was free and then verbally confirmed if he was willing to participate in the survey. Between January 23 and 27, 2018, surveyors requested approximately 300 drivers, of which 197 voluntarily participated in the survey. The drivers refused to join the survey because they were waiting for customers, tired, busy on phone or having lunch, and not in a good mood.

It took the average from $10 \mathrm{~min}$ to $15 \mathrm{~min}$ for each respondent to answer the questionnaire. Most respondents were Bajaj drivers and only three were Motodop drivers. Respondents were recruited with a financial incentive (i.e., 1 USD) for their time spent in the survey. About ten respondents refused to accept the incentive because they humbly wanted to contribute to this study. After the in- 
formation screening process, only data from 182 Bajaj drivers were with effective information.

\section{Analysis Results}

\subsection{Driver Characteristics}

Table 2 reports the descriptive characteristics of interviewed Bajaj drivers with RHAs. Majority were younger than 40 years old (80.2\%) and married (86.7\%). Regarding the highest education attainment, majority finished at least secondary school (85.3\%). This proportion is relatively higher than that (69.7\%) reported in [23], suggesting that Bajaj drivers with RHAs had higher education than the traditional paratransit drivers (i.e., Motodops and Remorks). Some $8.8 \%$ had dual jobs-they were not only the drivers of Bajaj, but also government officer, farmer, worker, or teacher. RHAs seem to create jobs that attracted people with various professional backgrounds-including employees (15.4\%), drivers (14.8\%), skilled workers (11.0\%), and sellers (6.0\%). The period of working as Bajaj drivers with RHAs ranged from one week up to 30 years, with the average of 22.4 months. Majority were new drivers; whose working period was less than a year (78.0\%). Minority had a driving license (29.1\%) and a vehicle insurance (6.0\%). $6.6 \%$ claimed that they were also members of two labor associations-that is, Cambodia for Confederation Development Association (2.2\%) and Independent Democracy of Informal Economy Association (4.4\%). These are the two largest labor associations in Cambodia [24].

The period that drivers had been using a smartphone ranged from one week to 13 years, with the average of 2.7 years. There were two types of smartphones' operating systems: android (86.5\%) and iOS (13.5\%). Android phones were more popular because their prices-mostly second-hand devices-were relatively cheaper than an iOS device (i.e., iPhone or iPad). With mobile internet service, the drivers could operate with RHAs. Majority registered to one RHA (77.5\%) - and without a strict internal rule set by RHFs, some drivers registered to 2 - 4 RHAs (22.5\%).

\subsection{Ride-Hailing Apps}

Table 3 reports the summary statistics of RHAs registered. There were eight different RHAs reported by the interviewed drivers. The four-most popular RHAs were PassApp (52.3\%), WeGo (19.2\%), UGO711 (15.9\%), and iTsumo (8.4\%). The average period since the drivers registered to RHAs ranges from 19 days to 5.6 months. The most recent registration was two days, while the longest period was up to three years ago. Each driver who registered to a RHF is required to pay a commission fee. The commission fee refers to the percentage of the total fare collected from a customer upon consuming paratransit service via the firm's RHA. The reported commission fees ranged from $0 \%$ to $20 \%$, with the average of 9.2\%. Although each RHF has a set of internal rules like the commission fee, the drivers seem to understand the fee in different way. As such, they reported 
Table 2. Socio-demographic characteristics of the interviewed drivers $(N=182)$.

\begin{tabular}{|c|c|c|c|}
\hline Variable & Percentage & Variable & Percentage \\
\hline \multicolumn{2}{|c|}{ Age } & \multicolumn{2}{|c|}{ Career prior working as driver } \\
\hline $19-29$ & $28.0 \%$ & Driver & $14.8 \%$ \\
\hline $30-39$ & $52.2 \%$ & Employee & $15.4 \%$ \\
\hline $40-49$ & $14.3 \%$ & Seller & $6.0 \%$ \\
\hline $50-60$ & $5.5 \%$ & Skilled worker & $11.0 \%$ \\
\hline \multicolumn{2}{|c|}{ Marital status } & Worker & $9.3 \%$ \\
\hline Single & $12.8 \%$ & Others & $7.8 \%$ \\
\hline Married & $86.7 \%$ & Missing & $35.7 \%$ \\
\hline Others & $0.5 \%$ & \multicolumn{2}{|c|}{ Vehicle insurance } \\
\hline \multicolumn{2}{|c|}{ Education } & Yes & $6.0 \%$ \\
\hline Never study & $1.1 \%$ & No & $94.0 \%$ \\
\hline Elementary & $13.7 \%$ & \multicolumn{2}{|c|}{ Member of a labor association } \\
\hline Secondary & $45.1 \%$ & Yes & $6.6 \%$ \\
\hline High school & $35.2 \%$ & No & $93.4 \%$ \\
\hline University & $5.0 \%$ & Perio & smartphone \\
\hline \multicolumn{2}{|c|}{ Driving license } & $\leq 6$ & $22.5 \%$ \\
\hline Car & $16.5 \%$ & $6-12$ & $17.6 \%$ \\
\hline Motorcycle & $10.4 \%$ & $12-24$ & $14.3 \%$ \\
\hline Both & $2.2 \%$ & $24-36$ & $15.9 \%$ \\
\hline No & $70.9 \%$ & $>36$ & $29.7 \%$ \\
\hline \multicolumn{2}{|c|}{ Period of working as driver, in months } & \multicolumn{2}{|c|}{ Smartphone's operating system } \\
\hline$\leq 3$ & $38.5 \%$ & Android & $86.3 \%$ \\
\hline $3-6$ & $25.8 \%$ & iOS & $13.2 \%$ \\
\hline $6-12$ & $13.7 \%$ & Both & $0.5 \%$ \\
\hline $12-24$ & $5.5 \%$ & \multicolumn{2}{|c|}{ Number of apps registered } \\
\hline$>24$ & $16.5 \%$ & 1 & $77.5 \%$ \\
\hline \multicolumn{2}{|c|}{ Dual jobs } & 2 & $15.4 \%$ \\
\hline Yes & $8.8 \%$ & 3 & $6.0 \%$ \\
\hline No & $91.2 \%$ & 4 & $1.1 \%$ \\
\hline
\end{tabular}

various fees, which lead to a variation of commission fees being reported. It should be noticed that, PassApp could still attract majority of drivers despite its relatively higher commission fee, compared with the fees of other RHAs. One possible explanation is that PassApp has already gained its reputation among many citizens of Phnom Penh. The drivers might have expected to gain higher revenue by accepting more customers via PassApp, even they had to pay a higher commission fee. It should also be noted that most drivers were required to 
Table 3. Summary statistics of ride-hailing apps registered $(N=182)$.

\begin{tabular}{ccccccccccc}
\hline \multirow{2}{*}{ App } & \multirow{4}{*}{ Obs. } & Share & \multicolumn{3}{c}{$\begin{array}{c}\text { Period since Registration, } \\
\text { in months }\end{array}$} & \multicolumn{5}{c}{$\begin{array}{c}\text { Commission Fee, } \\
\text { in percentage }\end{array}$} \\
\cline { 5 - 11 } & & & Mean & SD & Min & Max & Mean & SD & Min & Max \\
\hline PassApp & 125 & $52.3 \%$ & 4.68 & 3.69 & 0.07 & 24 & 14.2 & 1.9 & 4 & 20 \\
WeGo & 46 & $19.2 \%$ & 3.07 & 5.58 & 0.08 & 36 & 10.0 & 1.6 & 5 & 15 \\
UGO711 & 38 & $15.9 \%$ & 5.60 & 6.84 & 0.47 & 36 & 9.4 & 2.7 & 0 & 15 \\
iTsumo & 20 & $8.4 \%$ & 2.66 & 2.83 & 0.07 & 12 & 8.2 & 3.3 & 0 & 15 \\
EXNET & 5 & $2.1 \%$ & 2.85 & 2.32 & 0.23 & 6 & 6.3 & 4.8 & 0 & 10 \\
CAMGO & 2 & $0.8 \%$ & 3.05 & 4.17 & 0.10 & 6 & 11.0 & 14.1 & 10 & 12 \\
FastGo & 2 & $0.8 \%$ & 0.62 & 0.54 & 0.23 & 1 & 5.0 & 7.1 & 0 & 10 \\
TosTov & 1 & $0.4 \%$ & 5.00 & & 5.00 & 5 & 10.0 & & 10 & 10 \\
\hline
\end{tabular}

deposit a minimum amount of money in a temporary bank account for the commission charge, in order for them to be able to operate with RHAs (e.g., PassApp). This is more practical when considering the current working conditions of informal drivers in the city. As most drivers were poor and had no stable income, they had no obligation to have an official bank saving account. In line with this situation, many drivers needed to visit RHA offices to refill their temporary accounts.

Further, respondents were requested to describe three major reasons why they registered to an RHF-175 of them reported 227 reasons. Mixed reasons were received and were classified into three categories, namely to get more passengers (75.8\%), to get higher revenues (11.5\%), and other reasons (12.8\%) including modernization and no need a pick-up station. Similarly, respondents were requested to describe three good and three bad points they experienced with the RHAs registered. 152 drivers reported 219 good points and 62 drivers reported 79 bad points-their mixed responses were categorized as in Figure 2 (left) and Figure 2 (right), respectively. For the good points, majority of the drivers claimed that RHAs facilitated them in getting more customers and higher revenue (79.9\%). Some also reported that RHAs helped them to save time (5.9\%) and to avoid fare negotiation (4.6\%). Other good points include safety and maps/GPS navigation (9.6\%). For the bad points, the drivers claimed high commission fee charged by RHFs (38.0\%), the app errors (34.2\%), and the issues with customers (15.2\%). The other bad points include the strict internal rules set by the app companies (12.7\%). The app errors include internet and system errors. The customer issues include the trip cancelation and complaints. RHFs might want to improve these bad points in order to minimize negative image on their RHS. For example, RHFs should improve their RHA features to minimize errors, cooperate with high-speed internet company to support their RHA drivers, and encourage the drivers with special incentives or discounts. Minimal errors within the RHAs would also help reduce customer issues and maintain the reputation of RHFs. 


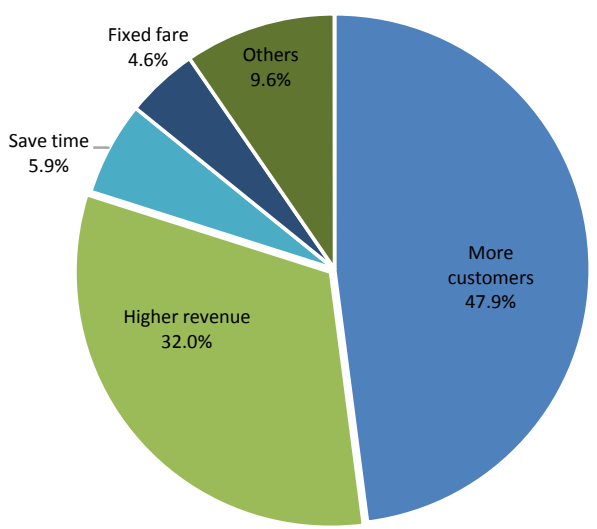

(left)

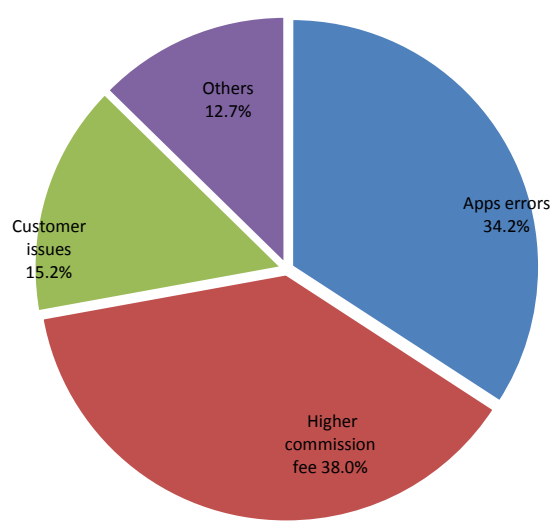

(right)

Figure 2. The good points (left) and the bad points (right) about using ride-hailing apps.

\subsection{Operational Services}

In part 2 of the questionnaire, respondents were requested to report their operational services before and after adopting RHAs. Their responses were summarized in Table 4. The overall operational services for all interviewed drivers who operated with RHAs are summarized under "After (overall)". In average, the drivers provided transport services 10.3 hours with 42.6 min lunch break per day. They could make up to 40 (average of 14.5) trips and transport up to 100 (average of 20.8) customers per day. The drivers could earn from 75 USD to 1000 USD, with the average of 430.8 USD per month. Their monthly expenses ranged from 10 USD to 450 USD, with the average of 128.6 USD. The expenses include gasoline and vehicle maintenance fees.

Approximately $40.0 \%$ of the interviewed drivers reported their operational services both before and after adopting RHAs, suggesting that they continued to serve paratransit services by embracing advance technology (i.e., RHAs). Their operational services were summarized separately under "Before" and "After", respectively. Two types of group mean comparison tests were performed to examine changes in the operational services before and after adopting RHAs. One is the comparison between "Before" and "After (overall)" using unpaired $t$-test with a degree of freedom (D.F.). The other is the comparison between "Before" and "After" using paired $t$-test. All $t$-tests are significant $(p<0.01)$, except that for daily working hours between "Before" and "After (overall)" which is not significant $(p>0.05)$.

We now examine the actual changes in the operational characteristics for specific drivers who have upgraded their services by adopting RHAs. Results from paired $t$-tests show an increase in daily working hours by $8.4 \%$ and a decrease in lunch break time by $26.2 \%$, in average. This suggests that the drivers became more active in providing paratransit services, with RHAs assisting them in finding more customers. Even during their lunch break period, the drivers could still accept the hailing customers on their smartphones if they were willing to do so. 
Table 4. Operational services before and after adopting ride-hailing apps.

\begin{tabular}{|c|c|c|c|c|c|c|c|}
\hline \multirow{2}{*}{ Variables } & \multirow{2}{*}{$N$} & \multirow{2}{*}{ Mean } & \multirow{2}{*}{ S.D. } & \multirow{2}{*}{ Min } & \multirow{2}{*}{ Max } & \multicolumn{2}{|c|}{ Comparison test } \\
\hline & & & & & & D.F. & $t$-test \\
\hline \multicolumn{8}{|c|}{ Daily working duration, in hours } \\
\hline After (overall) & 182 & 10.26 & 2.41 & 2.5 & 17 & 250 & 0.88 \\
\hline After & 70 & 10.80 & 2.29 & 2.5 & 16 & & $2.68^{\star *}$ \\
\hline Before & 70 & 9.96 & 2.30 & 5 & 16 & & \\
\hline \multicolumn{8}{|c|}{ Daily lunch break, in minutes } \\
\hline After (overall) & 182 & 42.63 & 33.37 & 0 & 240 & 250 & $-3.52^{\star *}$ \\
\hline After & 70 & 46.97 & 38.24 & 5 & 180 & & $-3.02^{\star \star}$ \\
\hline Before & 70 & 63.64 & 60.08 & 5 & 330 & & \\
\hline \multicolumn{8}{|c|}{ Number of daily trips } \\
\hline After (overall) & 182 & 14.47 & 6.38 & 3 & 40 & 251 & $5.82^{\star *}$ \\
\hline After & 71 & 14.65 & 6.83 & 3 & 40 & & $6.50^{* *}$ \\
\hline Before & 71 & 8.99 & 7.56 & 2 & 55 & & \\
\hline \multicolumn{8}{|c|}{ Number of daily passengers } \\
\hline After (overall) & 182 & 20.76 & 10.75 & 4 & 100 & 252 & $4.79^{\star *}$ \\
\hline After & 72 & 21.88 & 14.01 & 5.5 & 100 & & $5.34^{* *}$ \\
\hline Before & 72 & 13.45 & 11.55 & 5 & 90 & & \\
\hline \multicolumn{8}{|c|}{ Monthly revenues, in USD } \\
\hline After (overall) & 182 & 430.78 & 158.25 & 75 & 1000 & 251 & $6.31^{\star *}$ \\
\hline After & 71 & 416.65 & 152.69 & 80 & 750 & & $6.72^{\star \star}$ \\
\hline Before & 71 & 286.34 & 176.57 & 15 & 1000 & & \\
\hline \multicolumn{8}{|c|}{ Monthly expenses, in USD } \\
\hline After (overall) & 182 & 128.55 & 69.55 & 10 & 450 & 252 & $5.06^{* *}$ \\
\hline After & 72 & 117.86 & 74.74 & 10 & 450 & & $4.35^{\star \star}$ \\
\hline Before & 72 & 80.14 & 66.65 & 15 & 480 & & \\
\hline
\end{tabular}

Note: $1 \mathrm{USD} \approx 4,000 \mathrm{KHR}$ is assumed, as of January $2018 .{ }^{\star} p<0.05,{ }^{* *} p<0.01$.

Longer servicing hours have led to an increase in the average number of daily trips by $63.0 \%$ and customers by $62.7 \%$. Consequently, the drivers could increase monthly revenue by $45.5 \%$.

This is an improvement that also comes with additional monthly expenses of $47.1 \%$. In sum, the results indicate a significant improvement in the operational services for drivers who have embraced the advance technology like RHAs.

To see whether there are differences in the operational services for drivers operated with multiple RHAs, we performed additional comparison tests in Table 5. We first divided the respondents into two groups: one operated with one RHA (77.5\%) and the other operated with 2 - 4 RHAs (22.5\%). We then examined the 
Table 5. Operational services of drivers with different number of ride-hailing apps registered.

\begin{tabular}{ccccccc}
\hline \multirow{2}{*}{ Variable } & \multicolumn{2}{c}{ One app $(N=141)$} & $2-4$ apps $(N=41)$ & \multicolumn{2}{c}{ Welch's $t$-test } \\
\cline { 2 - 7 } & Mean & S.D. & Mean & S.D. & D.F. & $t$-test \\
\hline Daily working duration, in hours & 10.13 & 2.47 & 10.70 & 2.14 & 75.32 & -1.46 \\
$\begin{array}{c}\text { Daily lunch break, in minutes } \\
\text { Number of daily trips }\end{array}$ & 42.12 & 29.72 & 44.39 & 44.08 & 51.56 & -0.31 \\
Number of daily passengers & 20.54 & 11.34 & 21.52 & 8.49 & 87.73 & -0.60 \\
Monthly revenue, in USD & 416.84 & 152.73 & 478.72 & 169.25 & 61.20 & $-2.10^{*}$ \\
Monthly expenses, in USD & 120.47 & 60.97 & 156.34 & 88.62 & 52.05 & $-2.43^{*}$ \\
\hline
\end{tabular}

Note: 1 USD $\approx 4,000 \mathrm{KHR}$ is assumed, as of January $2018 .{ }^{\star} p<0.05,{ }^{* *} p<0.01$.

differences between the two groups using Welch's $t$-test. Results show that the mean values of operational services increased, but only monthly revenue and expenses were statistically significant $(p<0.05)$. This suggests that, although with similar working conditions (e.g., working hours, number of daily trips), the drivers with more RHAs could further increase their monthly revenue by $14.8 \%$ higher. With multiple RHAs, the drivers may choose to accept more longer-distance trips to increase the fare per trip on desire roads and time. Often, RHFs (e.g., PassApp) have specific rule not to allow their driver members registering to the other RHAs. In the current situation, however, this rule is not so strict and the drivers could register to multiple RHAs, which is a good strategy for them to enjoy a higher revenue.

We also conducted more statistical tests to see whether there were differences in the operational services with respects to drivers' socio-demographic characteristics, as shown in Table 2-that is, the groups of age, marital status, education, and period of working as a paratransit driver. One-way analysis of variance was applied for comparison of more than two groups, but it does not tell which group is more superior than the other groups. Results show significant differences in the average daily working hours with respects to different marital status $(F(2,179)=3.20, p=0.04)$, educational levels $(F(4,177)=2.83, p=0.03)$, and period of working as a paratransit driver $(F(4,177)=2.42, p=0.05)$. In addition, the average number of daily trips made by the drivers was found to be different with respects to different age groups $(F(3,178)=2.74, p=0.04)$. The average monthly revenues were also found to be different among drivers from different age groups $(F(3,178)=3.05, p=0.03)$, marital status $(F(2,179)=$ $3.89, p=0.02)$, and educational levels $(F(4,177)=2.43, p=0.05)$. The tests for other variables (e.g., daily lunch break, number of daily passengers) were non-significant $(p>0.05)$.

\subsection{Driver Behaviors}

This section explores the common behaviors of paratransit drivers with RHAs. 
First, respondents were requested to report the high demand hours, during which they experienced more RHA customers. Figure 3 shows the hourly share of demand for RHS. Majority of drivers reported that they could get more RHA customers during the peak hours from 7:00 to $8: 00(68.1 \%-74.7 \%)$ and from $16: 00$ to $18: 00(71.4 \%-87.9 \%)$. With these high demand hours in mind, the drivers would work smarter and be ready for their RHA customers.

In addition, the drivers were asked to describe three of their favorite standby locations during low demand hours. 249 locations were reported and categorized as in Figure 4 (left). Majority (89.9\%) liked to standby on-streets and near public places (e.g., residential areas, markets, hotels, restaurants, schools, and bus terminals). Basically, the drivers operated with RHAs require no specific standby stations. The drivers asserted that, after dropping off a customer, they looked for a vacant space with shadow along the streets to wait for the next customers booking via RHAs. When they were not in the working mood, they would simply turn off RHAs on their smartphones for not accepting customers. Besides, 180 drivers reported 283 favorite activities at the standby locations. These activities were summarized in Figure 4 (right). Majority (64.3\%) involved with leisure activities via smartphones (e.g., Facebook, music, movies, game), 12.4\% would wait for the next customers. Other activities include reading $(7.8 \%)$, chitchatting with friends (6.0\%), resting (5.3\%), having coffee (2.5\%), and others $(1.8 \%)$.

The additional behaviors of paratransit drivers with RHAs are reported in Table 6. In average, the drivers spent 6.7 min to go picking up a customer upon they accepted his/her booking via RHAs. About half (51.7\%) took less than 5 min, while $40.1 \%$ took 5 - 10 min to pick up RHA customers. This could be as fast as 1 min depending on the level of traffic congestion as well as the customers' origins. The drivers further reported that they would carefully accept RHA customers whose pick-up locations were far from them (e.g. 5 - $10 \mathrm{~min}$ ), especially during the congested hours. This is because they wanted to avoid customers from waiting longer time, which could possibly lead to complaints and cancellations of the booking trips. The drivers were also aware of the punishments set by RHFs for whom frequently cancel the trips booked by customers. Experienced drivers would know this situation well and chose to react accordingly. When asking how many times they failed to locate the booking customers, $14.8 \%$ reported that they never missed their customers, $35.2 \%$ lost from one to

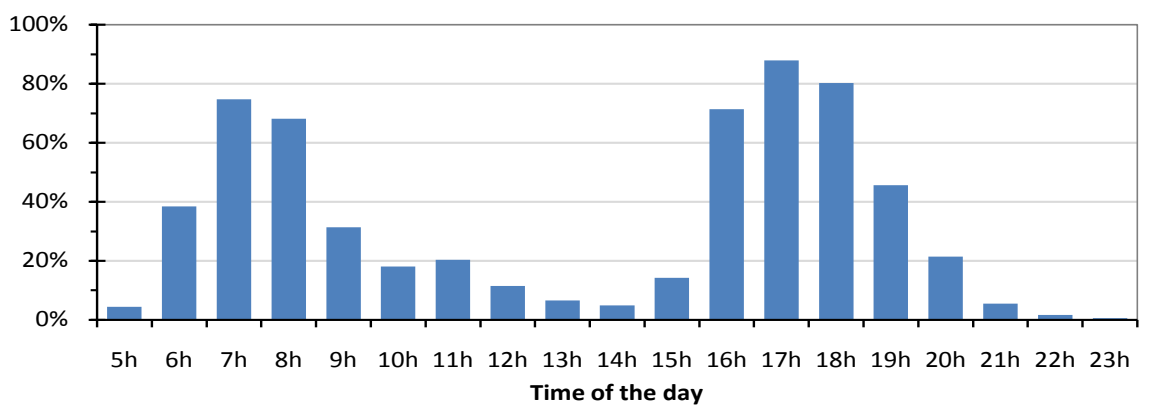

Figure 3. High demand hours experienced by interviewed drivers with RHAs. 


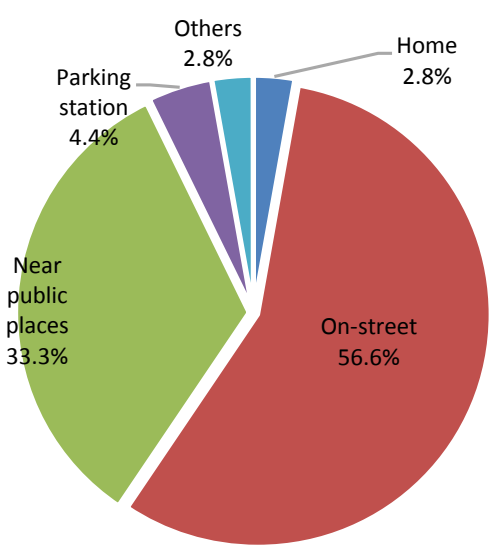

(left)

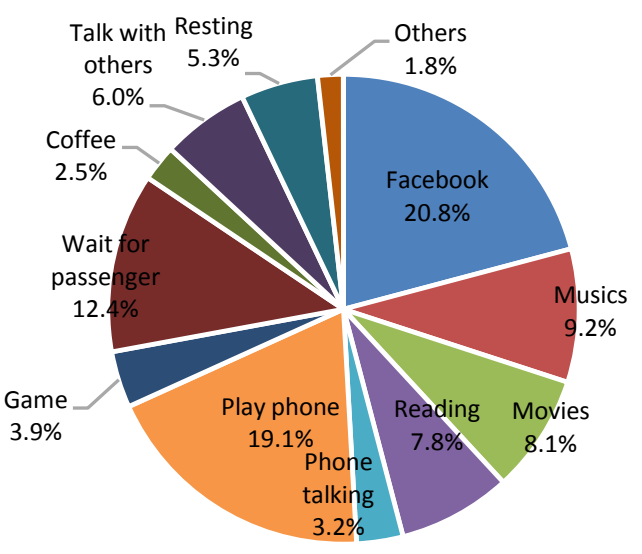

(right)

Figure 4. The standby locations (left) and the activities (right) during low demand hours.

Table 6. Additional behaviors of the interviewed drivers with ride-hailing apps.

\begin{tabular}{cccc}
\hline Variable & Percentage & Variable & Percentage \\
\hline Time required to pick up a customer, in minutes & Whether to cruise for passengers \\
$<5$ & $51.7 \%$ & Yes & $35.2 \%$ \\
$5-10$ & $40.1 \%$ & No & $64.8 \%$ \\
$>10$ & $8.2 \%$ & Frequency of cruise per day \\
Frequency of losing app passengers per month & 0 & $64.8 \%$ \\
0 & $14.8 \%$ & $1-3$ & $11.5 \%$ \\
$1-5$ & $35.2 \%$ & $4-6$ & $14.3 \%$ \\
$6-10$ & $29.7 \%$ & $>7$ & $9.3 \%$ \\
$>10$ & $20.3 \%$ & Cruising duration per day, in minutes \\
Frequency of checking apps per hour & 0 & $64.8 \%$ \\
0 & $53.3 \%$ & $1-15$ & $9.9 \%$ \\
1 & $17.0 \%$ & $16-30$ & $7.1 \%$ \\
$2-3$ & $25.8 \%$ & $31-45$ & $9.3 \%$ \\
$>3$ & $3.9 \%$ & $>45$ & $8.8 \%$ \\
\hline
\end{tabular}

five, and $50.0 \%$ lost more than six customers per month. The failures to locate customers were caused by several factors including the issues within RHAs, slow internet, errors in digital map and GPS, and the matters with customers (e.g., waiting at an inconvenient place where drivers were unable to pinpoint).

When there were no customers, the drivers checked their RHAs about once in average, and up to 15 times per hour. About half (53.3\%) did not check RHAs, $42.8 \%$ checked from once to 3 times, and $3.9 \%$ checked more than 3 times per hour. Usually, RHAs would alert the drivers when there were incoming booking customers. However, they may come to check the apps because they wanted to review their working history and updates, including incentive benefits and balance of deposit account. Although RHAs assisted the drivers to get customers, 
$35.2 \%$ still tried to cruise for additional passengers along the streets. They cruised 6.5 times and spent $42.5 \mathrm{~min}$ per day in average looking for additional customers. On daily basis, majority of them spent from $1 \mathrm{~min}$ to $45 \mathrm{~min}(74.7 \%)$ and cruised from once to 6 times (73.3\%). In addition, the drivers explained up to three main reasons why they decided to cruise for additional customers. Eighty-three drivers reported 108 reasons, which were categorized as: because they wanted to get more customers (53.7\%), they wanted to increase daily revenue $(35.2 \%)$, and there were errors within RHAs, including internet and system errors $(11.1 \%)$. When asking whether they wanted a proper standby station waiting RHA customers, $72.0 \%$ gave positive responses. Such standby station could help reduce the number of paratransit drivers idling on-streets, and thus traffic congestion on the city streets to some extents, especially during peak hours.

\subsection{Operating Speed and Routes}

To collect data regarding the operating speed and routes of paratransit drivers with RHAs, we first requested about 30 drivers to attach each of their vehicles with a portable GPS device (GPS Route Logger GT-730FL-S, Canmore Electronics Co., Ltd., Hsinchu, Taiwan). This device records time and geographical coordinates (i.e., latitude, longitude, and altitude), and speed for every five seconds. Eleven drivers agreed to have their vehicle attached with the GPS device, each for a single day 9:00 - 22:00, January 26-27, 2018. Other drivers refused to GPS attachments because they concerned with violations of the rules in ride-haling firms, they were busy, and they simply rejected without offer any reasons. Table 7 gives the summary statistics of the collected GPS data. The total GPS-measured time ranged from 6.4 hours to 12.0 hours, with the average of 8.6 hours. The servicing distance ranged from $36.1 \mathrm{~km}$ to $120.5 \mathrm{~km}$, with the average of $79.4 \mathrm{~km}$. The total moving time ranged from 2.1 hours to 6.4 hours, with the average of 4.2 hours. The average operational speed was measured as slow as $4.0 \mathrm{~km} / \mathrm{h}$ and as fast as $12.1 \mathrm{~km} / \mathrm{h}$. The average maximum speed of Bajajs is $46.3 \mathrm{~km} / \mathrm{h}$, which is relatively faster than that $(35.7 \mathrm{~km} / \mathrm{h})$ of traditional $\mathrm{Re}$ morks [23]. The maximum speed could be as high as $60.0 \mathrm{~km} / \mathrm{h}$, almost equivalent to the highest speed specification indicated from Bajaj manufacturer. Figure 5 illustrates the operating routes of Bajaj drivers with RHAs in Phnom Penh. While fewer trips seem to be scattered in the suburban areas, more trips concentrated in the downtown area, penetrating through both major and small roads. This may also suggest that majority of the Bajaj trips via RHAs were short-distance trips within the downtown area.

\subsection{Subjective Responses}

Respondents evaluated seven subjective questions related to their satisfaction and future anticipation towards RHAs, based on the 5-point scale (1: very unlikely, 2: unlikely, 3: neither, 4: likely, 5: very likely). Their evaluation scores were reported in Figure 6. Most drivers (96.7\%) rated high scores (scored of 4 or 5), 
Table 7. Summary statistics of the collected GPS data $(N=11)$.

\begin{tabular}{ccccc}
\hline Variable & Mean & S.D. & Min & Max \\
\hline Total GPS-measured time, in hours & 8.6 & 1.8 & 6.4 & 12.0 \\
Total GPS-measured distance, in km & 79.4 & 25.1 & 36.1 & 120.5 \\
Total moving time, in hours & 4.2 & 1.5 & 2.1 & 6.4 \\
Total stopped time, in hours & 4.4 & 1.2 & 2.0 & 6.3 \\
Average speed, in km/h & 8.8 & 2.3 & 4.0 & 12.1 \\
Maximum speed, in km/h & 46.3 & 7.5 & 35.0 & 60.0 \\
\hline
\end{tabular}

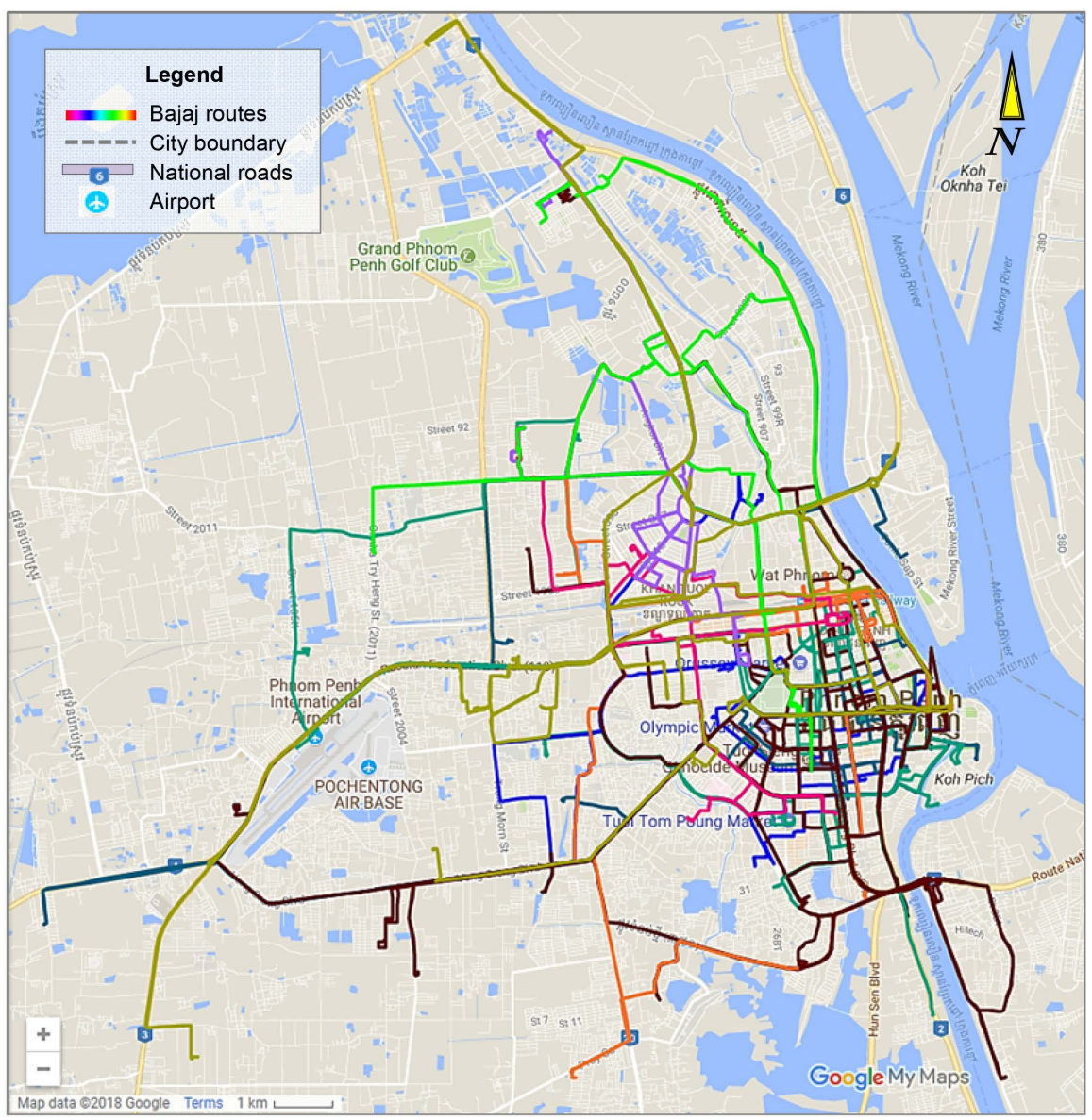

Figure 5. GPS data showing operational routes of Bajaj drivers with RHAs in Phnom Penh. Majority of Bajaj trips via RHAs appeared to be short-distance trips within the downtown area.

indicating that they truly satisfied with the RHAs. They claimed that RHAs helped improve their overall paratransit services (94.5\%) and safety and security (88.5\%). Their living conditions were also remarkably improved after adopting RHAs (94.5\%). When asking whether they would change their career as a paratransit driver, given that their living conditions became better, $42.9 \%$ hesitated (scores of 3 ) and $43.4 \%$ would shift to the other jobs. Regarding the future anticipation, majority (56.0\%) agreed that the government should control the 


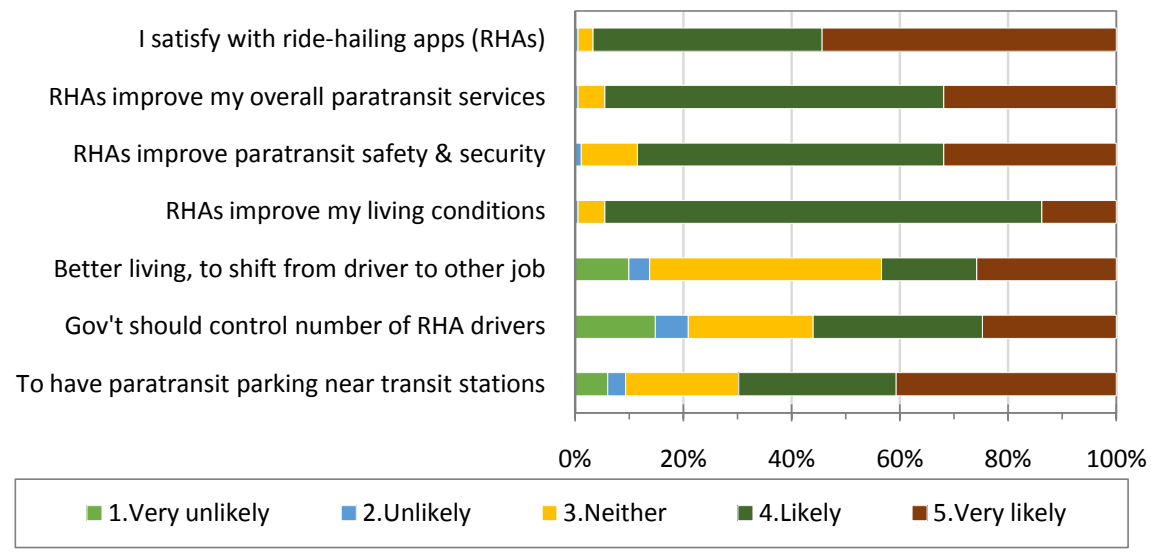

Figure 6. Subjective responses towards ride-hailing apps.

number of paratransit drivers operated with RHAs. They (69.8\%) also thought that it would be better to have proper standby stations near bus stops or railway stations in the city.

\subsection{Discussion}

Among the interviewed Bajaj drivers in Phnom Penh, about 40.0\% were identified as former paratransit drivers who have upgraded their services by adopting RHAs. Adaptation is the key to survival. These drivers might have anticipated changes in the demand for paratransit services following market penetration of RHSs-and thus, they have gradually upgraded their vehicles (e.g., from Motodops/Remorks to Bajajs) and adopted RHAs in order to improve their operational services and livelihood. The improvement was well supported by the data in this study. As about $40 \%$ were former paratransit drivers, this also means that about $60.0 \%$ were new drivers who came into paratransit market directly with RHAs. This proportion justifies that, although RHAs may affect traditional paratransit operators, RHAs have indeed generated extra jobs into labor market, especially for many low-income or unskilled people. However, new drivers may also include less experienced or less professional individuals to serving paratransit services, which in turns raises questions on their operational safety.

If the traditional paratransit operators do not embrace new technology, following recent changes in the paratransit market, they may eventually lose their market to RHA drivers. One observation is that, the arrival of Bajajs with RHAs have lessened the number of Remorks on the city streets. While RHA drivers required no specific pick-up stations, traditional Remorks seemed to spend more time waiting their customers at the secured pick-up locations such as near the airport, hotels, markets, and bus stops/terminals. Other potential customers for traditional Remorks include those who did not use a smartphone and loyal customers (e.g., relatives, friends, and neighbors). Another observation is that only a small number of Remork drivers registered to RHAs. Based on opinions of the interviewed drivers, operating Remorks with RHAs would not be much attractive among RHA users because Remorks consume more gasoline, which would 
cost higher comparing to Bajajs that consume cheaper liquefied petroleum gas. In line with this situation, the fare structure for Remorks has been defined to be relatively higher than that of Bajajs. For example, the fare of PassApp began at 3000 and $4000 \mathrm{KHR}$ ( 0.75 and 1.0 USD) with the rate of 1200 and $1300 \mathrm{KHR}(0.3$ and 0.325 USD) per subsequent kilometer for Bajajs and Remorks, respectively. The fare was distance-based, but not time-based. When Remork drivers wish to operate with RHAs, they may also want to upgrade their vehicles-e.g., from Remork to Bajaj-in order to be more profitable via lower operating cost. Although there was news reported that the demand for traditional paratransit services have been squeezed by RHA drivers, no protests against RHAs have been seen so far. Even there would be protests, as these paratransit drivers have been considered as informal transport operators; however, they may receive little attention from the government. One of the best strategies for the impacted traditional paratransit drivers might be that they should adapt themselves in the era of advance technology-e.g., by offering their customers better transport services via RHAs. As the popularity of RHAs continues to arise, the government may want to consider minimum regulations (e.g., standardized fare structure, safety regulations, and labor protection), which shall benefit all relevant stakeholders, including general citizens and paratransit operators.

\section{Conclusions}

This study assessed changes in the operational services among paratransit operators with RHAs in Asian developing cities. The changes were assessed via data from interview survey with 182 Bajaj drivers who operated with RHAs in Phnom Penh, as the case study. Results showed that approximately $40.0 \%$ of the drivers-who have upgraded their services by adopting RHAs-could increase the number of their daily trips and customers by about $63.0 \%$. They could also increase their monthly revenue by $45.5 \%$. Those who operated with multiple RHAs could further increase their monthly revenue by $14.8 \%$, compared with those who operated with single RHA. In sum, most drivers (>88.0\%) satisfied with RHAs and acknowledged that these RHAs helped improve their overall paratransit services as well as their living conditions.

The combination of Bajajs and RHAs (i.e., LAMAT) is an example of advanced utilization of old-fashioned paratransit modes in Asian developing countries. Such combination has attracted not only traditional paratransit operators (i.e., the case study showed $40.0 \%$ ), but also new drivers (60.0\%) to provide paratransit services with RHAs. Results from the case study implied that RHAs would be opportunities for those paratransit drivers who have adopted them, while they would be threats for those who have not. Despite concerns over the impacts of RHAs on traditional paratransit operators, RHAs might help improve urban mobility, add alternative transport options, and reduce traffic congestion via reduction in private vehicles. Since RHAs appear to have more benefits than drawbacks, traditional paratransit operators should adapt themselves to new technology-so that, they could meet the transport needs of citizens in modern 
society. Otherwise, traditional paratransit operators would continue to lose their customers, following higher levels of RHA market penetration. This is surely the choice of customers, who usually prefer more affordable and better transport services. Future study should focus on users' perspective, regarding their preferences and negative experiences with RHAs. Analyzing the effects of RHAs on mass transit ridership could also be useful input for policymakers to consider appropriate and flexible regulations for RHS in Asian developing cities, where there is lack of mass transit system and paratransit remains an indispensable mode.

\section{Acknowledgements}

This study was conducted as part of Toshiba-Tokyo Tech Collaborative Research Project. The first author is grateful to the Nippon Foundation for financial support. The authors thank Mr. CHHOUK Chhay Horng and four anonymous students at the Institute of Technology of Cambodia for their helps with the data collection, and Ms. Pharinet PHENG for the proofreading. The contents of this paper reflect the viewpoints of the authors, who are responsible for any errors.

\section{Conflicts of Interest}

The authors declare no conflicts of interest regarding the publication of this paper.

\section{References}

[1] Clewlow, R.R. and Mishra, G.S. (2017) Disruptive Transportation: The Adoption, Utilization, and Impacts of Ride-Hailing in the United States. Institute of Transportation Studies, University of California, Davis.

[2] He, F., Wang, X., Lin, X. and Tang, X. (2018) Pricing and Penalty/Compensation Strategies of a Taxi-Hailing Platform. Transportation Research Part C: Emerging Technologies, 86, 263-279. https://doi.org/10.1016/j.trc.2017.11.003

[3] Adriano, A.M.M. and Su, C.C.S. (2017) Out with the Old, in With the New: A Study on the Vehicle Hailing Preferences of Filipino Taxi Riders Based on Participation Intent. International Journal of Real Estate Studies, 11, 75-81.

[4] He, F. and Shen, Z.-J. (2015) Modeling Taxi Services with Smartphone-Based E-Hailing Applications. Transportation Research Part C: Emerging Technologies, 58, 93-106. https://doi.org/10.1016/j.trc.2015.06.023

[5] Schmitz, C., Bartsch, S. and Meyer, A. (2016) Mobile App Usage and Its Implications for Service Management-Empirical Findings from German Public Transport. Procedia-Social and Behavioral Sciences, 224, 230-237. https://doi.org/10.1016/j.sbspro.2016.05.492

[6] Masui, R. and Yai, T. (2018) A Study on LAMAT with New Technology and Its Future Prospects in Asian Cities. Japan Society of Civil Engineers, 74. (In Japanese)

[7] Wang, X., He, F., Yan, H. and Gao, H.O. (2016) Pricing Strategies for a Taxi-Hailing Platform. Transportation Research Part E: Logistics and Transportation Review, 93, 212-231. https://doi.org/10.1016/j.tre.2016.05.011

[8] Phun, V.K. and Yai. T. (2016) State of the Art of Paratransit Literatures in Asian Developing Countries. Asian Transport Studies, 4, 57-77.

[9] Tan, F.T.C., Tan, B., Lu, A. and Land, L. (2017) Delivering Disruption in an Emergent Access Economy: A Case Study of an E-Hailing Platform. Communications of 
the Association for Information Systems, 41, 497-516. https://doi.org/10.17705/1CAIS.04122

[10] Sun, Z., Yu, M., Zeng, J., Wang, H. and Tian, Y. (2017) Assessment of the Impacts of App-Based Ride Service on Taxi Industry: Evidence from Yiwu City in China. Compendium of Papers of Transportation Research Board 96th Annual Meeting, Washington DC, 8-12 January 2017, 1-12.

[11] Phun, V.K., Kato, H. and Chalermpong, S. (2018) Paratransit as a Connective Mode for Mass Transit Systems in Asian Developing Cities: The Bangkok Case.

[12] Ratanawaraha, A. and Chalermpong, S. (2015) Monopoly Rents in Motorcycle Taxi Services in Bangkok, Thailand. Transportation Research Record: Journal of the Transportation Research Board, 2512, 66-72. https://doi.org/10.3141/2512-08

[13] Harding, S., Kandlikar, M. and Gulati, S. (2016) Taxi Apps, Regulation, and the Market for Taxi Journeys. Transportation Research Part A: Policy and Practice, 88, 15-25. https://doi.org/10.1016/j.tra.2016.03.009

[14] Sadowsky, N. and Nelson, E. (2017) The Impact of Ride-Hailing Services on Public Transportation Use: A Discontinuity Regression Analysis. Vol. 13, Economics Department Working Paper Series, 1-26.

[15] Lim, K.B., Yeo, S.F., Goh, M.L. and Gan, J.A.X. (2018) A Study on Consumer Adoption of Ride-Hailing Apps in Malaysia. Journal of Fundamental and Applied Sciences, 10, 1132-1142.

[16] Pham, A., et al. (2017) Private Ride: A Privacy-Enhanced Ride-Hailing Service. Proceedings on Privacy Enhancing Technologies, Minneapolis, 18-21 July 2017, $1-17$.

[17] Wollenberg, A. and Waty, L. (2017) Perceived Value and Transportation References: A Study of the Ride-Hailing Transportation Sector in Jakarta. Journal of Economics, Business and Management, 5, 138-142. https://doi.org/10.18178/joebm.2017.5.3.501

[18] JICA-PPUTMP (2014) Project for Comprehensive Urban Transport Plan in Phnom Penh Capital City (PPUTMP). Japan International Cooperation Agency.

[19] Phun, V.K., Kato, H. and Yai, T. (2018) Traffic Risk Perception and Behavioral Intentions of Paratransit Users in Phnom Penh. Transportation Research Part F, 55, 175-187. https://doi.org/10.1016/j.trf.2018.03.008

[20] Phun, V.K., Pheng, P. and Yai, T. (2015) Using Ordered Probit Modeling to Assess Perceived Bus Performance in Phnom Penh. Journal of the Eastern Asia Society for Transportation Studies, 11, 1155-1172.

[21] Rahman, M.S.U. and Nahrin, K. (2012) Bus Services in Dhaka City-Users' Experiences and Opinions. Journal Bangladesh Institute of Planners, 5, 93-105.

[22] Phun, V.K., Kato, H. and Yai, T. (2017) Characteristics and Perceptions of Paratransit Users in Phnom Penh. Journal of the Eastern Asia Society for Transportation Studies, 12, 2215-2232.

[23] Phun, V.K., Lim, I. and Yai, T. (2015) The Characteristics of Paratransit Operation and Fare in Phnom Penh. Journal of the Eastern Asia Society for Transportation Studies, 11, 1307-1327.

[24] Phun, V.K., Masui, R. and Yai, T. (2015) The Future Prospects of Paratransit Services in Cambodia. Proceedings of the 7 th Regional Symposium on Infrastructure Development, Bangkok, 5-7 November 2015, 221-226. 